\title{
Ptosis following cataract and trabeculectomy surgery
}

\author{
J P DEADY, N J PRICE, AND G A SUTTON \\ From the Birmingham and Midland Eye Hospital, Birmingham B3 2NS
}

SUMMARY A prospective study was carried out to estimate the incidence and severity of ptosis following cataract extraction and trabeculectomy. A postoperative ptosis of $2 \mathrm{~mm}$ or more was found in $6.2 \%$ of all cases. In this series the incidence of ptosis following surgery under local anaesthesia was greater than that under general anaesthesia. The aetiology and management of this complication are discussed.

The incidence of ptosis following ocular surgery has not been widely reported. Paris and Quickert defined postoperative ptosis following cataract extraction as $2 \mathrm{~mm}$ or more of drooping of the upper eyelid persisting for more than six months. ${ }^{1}$ They asked 27 ophthalmologists about the frequency of this complication and derived estimates ranging from 0 to $10 \%$, the most common estimate being 1 to $2 \%$. In a study of patients undergoing cataract and glaucoma surgery, Alpar using the same criteria for ptosis found the incidence to be $11.4 \%$ following local anaesthesia and $1.5 \%$ following general anaesthesia. ${ }^{2}$ From figures reported by Kaplan et al. ${ }^{3}$ the incidence following cataract extraction under local anaesthesia would appear to be $13 \cdot 5 \%$.

The aetiology of postoperative ptosis is uncertain but thought to be a dehiscence or disinsertion of the levator aponeurosis during surgery. Paris and Quickert found disinsertion of the aponeurosis in two patients with ptosis following cataract extraction. ${ }^{1}$ They suggested that prolonged upper lid oedema after surgery leads to disinsertion in older patients who have vulnerable aponeuroses. Aponeurotic defects may also be present in patients with involutional ptosis, some of whom have had previous orbital swelling, eyelid oedema, or blepharochalasis. ${ }^{148}$ The main clinical features of ptosis due to a dehiscence or disinsertion of the levator aponeurosis are a high or absent lid crease, thinning of the ptotic eyelid above the tarsal plate, good or excellent levator function, ${ }^{6}$ and deepening of the upper sulcus. ${ }^{9}$

Opinion varies on the insertion of the levator aponeurosis. ${ }^{10}$ Many authors regard the upper eyelid skin crease as being formed by fibres from the

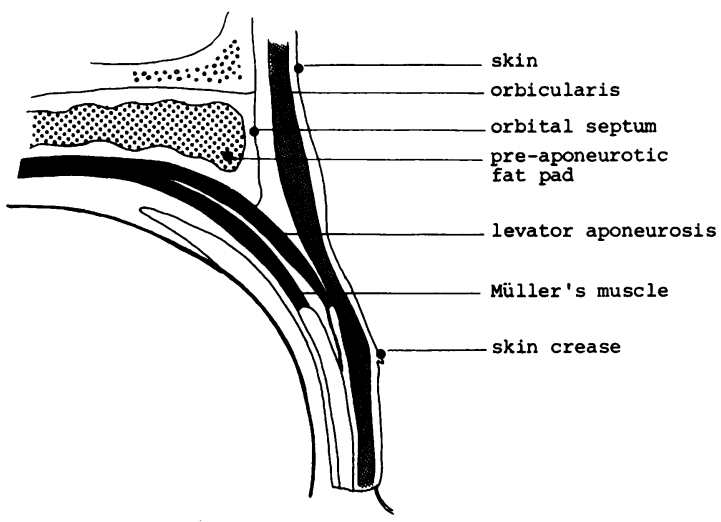

Fig. 1 Upper eyelid. Normal anatomy.

aponeurosis which are inserted into the skin. However, Collin et al. ${ }^{9}$ showed that the upper eyelid skin crease is formed by the insertion of the levator aponeurosis into the septa between the orbicularis

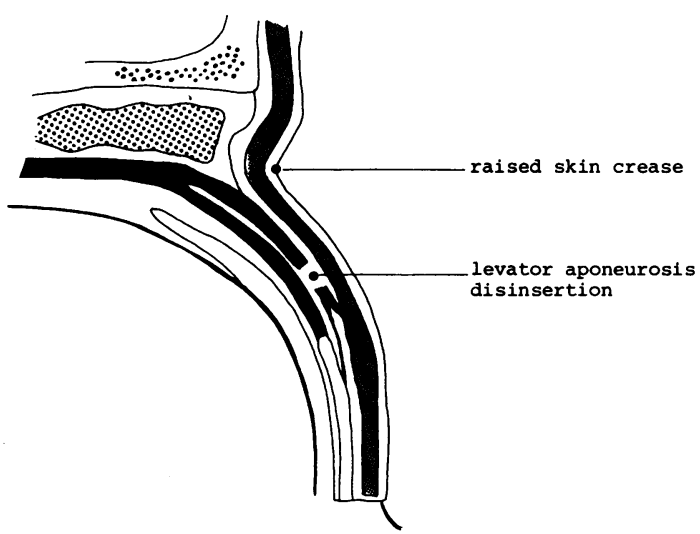

Fig. 2 Upper eyelid. Levator aponeurosis disinsertion. 
muscle bundles and not into the skin (Fig. 1). They reasoned that this would explain the high eyelid fold associated with a disinsertion of the aponeurosis. If the aponeurosis becomes disinserted or stretched, the original eyelid crease is lost and the levator retracts, pulling the orbital septum with it (Fig. 2). The orbicularis is pulled backwards, as it is firmly bound to the orbital septum. The eyelid skin follows the orbicularis, and a new higher eyelid crease is formed as the orbital septum is pulled into the orbit. This process is enhanced if the preaponeurotic fat pad is atrophic. ${ }^{9}$

Postoperative ptosis has been described as a significant complication of intraocular surgery. ${ }^{3}$ Alpar stated that there may be a cosmetic and often functional defect, ${ }^{2}$ which does suggest that in some cases the ptosis may be severe.

This prospective study was undertaken to investigate the incidence and severity of postoperative ptosis following cataract extraction and trabeculectomy.

\section{Patients and methods}

Consecutive patients were assessed on admission prior to unilateral cataract extraction or trabeculectomy. Excluded from the study were patients with a history of thyroid eye disease, external eye disease, or previous ocular or lid surgery on the preoperative side.

The following observations were made on both eyes before and after operation: (1) palpebral aperture in the primary position, (2) levator action, (3) height of the upper lid crease above the lid margin in downgaze, and (4) an assessment of the depth of the upper lid sulcus.

The following operative details were recorded: (1) surgical procedure, (2) type of anaesthesia, and (3) occurrence of a superior rectus haematoma. A superior rectus bridle suture was used in all procedures.

A pre-existing ptosis was defined as the difference between the palpebral apertures measured before surgery. We defined postoperative ptosis as a decrease of $2 \mathrm{~mm}$ or more in the palpebral aperture of the operated eye relative to the other eye persisting for at least six months after surgery in the absence of ocular or lid inflammation. The unoperated side therefore served as a control. Patients with a postoperative ptosis of $1 \mathrm{~mm}$ or more were reviewed for at least six months or until the ptosis had resolved if earlier. Any patients with postoperative ptosis who within six months required further surgery or were lost to follow-up were eliminated from the study.

Discrete data were compared by the $\chi^{2}$ test with Yates's correction or, where the frequencies were smaller, Fisher's exact test. Semi-continuous data, such as relative change in palpebral apertures, were compared by the Wilcoxon rank sum test and corresponding medians and ranges quoted.

\section{Results}

One hundred and fifty patients were initially examined, and of these 140 completed follow-up. Of the 10 remaining patients four had a second surgical procedure, four were lost to follow-up, and two died. Six patients went on to have surgery on their second eye in the absence of ptosis following their first procedure. Thus 146 operations (116 cataract extractions and 30 trabeculectomies, 64 male and 82 female eyes, median age 72 years, range 23-97 years) were performed by six consultants and 15 surgeons in training.

The postoperative change in palpebral aperture varied from a decrease of $3.5 \mathrm{~mm}$ to an increase of $2 \mathrm{~mm}$ relative to the unoperated side. There was no postoperative ptosis in $70 \%(102$ cases $)$. The majority of the remaining $30 \%$ ( 44 cases) developed less than $2 \mathrm{~mm}$ of ptosis. The incidence of postoperative ptosis of $2 \mathrm{~mm}$ or more as previously defined was $6.2 \%$ (nine of 146 cases, $95 \%$ confidence interval $2 \cdot 2-10 \cdot 2 \%$, median follow-up nine months).

Cases that developed postoperative ptosis had no pre-existing ptosis on the preoperative side. In contrast, they did have significantly more preexisting ptosis on the unoperated side than those that did not develop ptosis $(\mathrm{p}<0.001)$.

We found no significant difference $(p>0 \cdot 1)$ between the median age of patients with postoperative ptosis (67 years) and those without (72 years). Although females accounted for $78 \%$ (seven of nine cases) of those with ptosis and 55\% (75 of 137 cases) of those without, this difference was not found to be significant $(\mathrm{p}>0 \cdot 1)$.

The incidence of ptosis following local anaesthesia (11.5\%, three of 26 cases) was found to be higher than that following general anaesthesia $(5 \%$, six of 120 cases). However, the numbers of cases in these groups were insufficient to detect small significant differences.

Five patients had a superior rectus haematoma during placement of the bridle suture, none of whom developed ptosis. 18.5\% (27 of 146 cases) developed at least $1 \mathrm{~mm}$ of ptosis, which later resolved (median follow-up seven months). $4 \cdot 1 \%$ (six cases) developed ptosis which never exceeded $1.5 \mathrm{~mm}$ (median follow-up nine months). No patients had a ptosis which increased in severity within the follow-up period.

Levator function remained unaltered in patients with postoperative ptosis. An increase in height of 
the lid fold and deepening of the upper lid sulcus were difficult to assess. Although two patients with ptosis did show such changes, these occurred in patients without ptosis also.

\section{Discussion}

The incidences of postoperative ptosis following local and general anaesthesia in this study are similar to those found by others and we confirm a higher incidence following local anaesthesia. ${ }^{23}$

The fact that no eyes with pre-existing ptosis developed an increased ptosis postoperatively could be explained if a pre-existing aponeurotic defect had reached its maximum extent before surgery. Our finding that patients who developed a postoperative ptosis tended to have a pre-existing ptosis on the opposite side supports the theory that aponeurotic defects tend to become bilateral. ${ }^{6}$ This group of patients with a vulnerable aponeurosis is at risk of developing postoperative ptosis.

Trauma or haemorrhage in the superior rectus muscle is one operative factor thought to result in postoperative ptosis. ${ }^{2}$ Practically all patients who had a superior rectus haematoma were found by Alpar to develop postoperative ptosis, ${ }^{2}$ but it is noteworthy that no patients in our study did so. Cataract surgery performed without a superior rectus bridle suture is said to be associated with a lower incidence of postoperative ptosis ${ }^{3}$ (Bullock JD, personal communication, 1988).

In the evolution of postoperative ptosis the two cases reported by Paris and Quickert developed an increasing ptosis over 12 months. ${ }^{1}$ Kaplan et al. also reported a worsening ptosis in $12 \%$ of postoperative patients over six months. ${ }^{3}$ We had no cases of progressive ptosis. As $64 \cdot 3 \%$ (27 of 42 cases) of ptoses of at least $1 \mathrm{~mm}$ resolved within six months in our study, we would agree with others that it would be prudent to wait at least six months ${ }^{3}$ or until six months have elapsed without improvement ${ }^{11}$ before contemplating surgery.

For small degrees of ptosis surgical correction is rarely indicated. Often elderly patients complain of ptosis only when it interferes with vision. It has not been ascertained how frequently postoperative ptosis requires correction for cosmetic or functional reasons, but in our study surgery has not been considered necessary.

Repositioning of the disinserted levator apo- neurosis on the anterior tarsal plate is the preferred method of surgical correction in patients with this form of acquired ptosis and has been shown to give good results with minimal trauma to other lid structures. ${ }^{10-8}$ This method allows for later adjustment of under- and overcorrections. ${ }^{5}$ Others prefer Müller muscle-conjunctiva resection. ${ }^{1213}$ The Fasanella-Servat procedure ${ }^{14}$ and its modifications, ${ }^{1516}$ although sometimes advocated for lesser degrees of this type of ptosis, would appear to be an inappropriate approach, as temporal overcorrections can occur, ${ }^{4}$ and a failure to rectify the aponeurotic defect may result in late recurrences. ${ }^{7}$

The authors thank the consultant ophthalmic surgeons of the Birmingham and Midland Eye Hospital for permission to study their patients. We also thank Miss A E T Searle, FRCS, and Mrs C Rawlins for their assistance.

\section{References}

1 Paris GL, Quickert MH. Disinsertion of the aponeurosis of the levator palpebrae superioris muscle after cataract extraction. Am J Ophthalmol 1976; 81: 337-40.

2 Alpar JJ. Acquired ptosis following cataract and glaucoma surgery. Glaucoma 1982; 4: 66-8.

3 Kaplan LJ, Jaffe NS, Clayman HM. Ptosis and cataract surgery. A multivariant computer analysis of a prospective study. Ophthalmology 1985; 92: 237-42.

4 Shore JW, McCord CD. Anatomic changes in involutional blepharoptosis. Am J Ophthalmol 1984; 98: 21-7.

5 Jordan DR, Anderson RL. A simple procedure for adjusting eyelid position after aponeurotic ptosis surgery. Arch Ophthalmol 1987; 105: 1288-91.

6 Anderson RL, Dixon RS. Aponeurotic ptosis surgery. Arch Ophthalmol 1979; 97: 1123-8.

7 Jones LT, Quickert MH, Wobig JL. The cure of ptosis by aponeurotic repair. Arch Ophthalmol 1975; 93: 629-34.

8 Dortzbach RK, Sutula FC. Involutional blepharoptosis. Arch Ophthalmol 1980; 98: 2045-9.

9 Collin JRO, Beard C, Wood I. Experimental and clinical data on the insertion of the levator palpebrae superioris muscle. $A m J$ Ophthalmol 1978; 85: 792-801.

10 Anderson RL, Beard C. The levator aponeurosis. Arch Ophthalmol 1977; 95: 1437-41.

11 Fox SA. Ophthalmic plastic surgery. New York: Grune and Stratton, 5th ed. 1976: 410.

12 Putterman AM, Urist MJ. Müller muscle-conjunctiva resection. Technique for treatment of blepharoptosis. Arch Ophthalmol 1975; 93: 619-23.

13 Putterman AM, Urist MJ. Müller muscle-conjunctiva resection ptosis procedure. Ophthalmic Surg 1978; 9: 27-32.

14 Fasanella RM, Servat J. Levator resection for minimal ptosis: another simplified operation. Arch Ophthalmol 1961; 65: 493-6.

15 Fasanella RM. Surgery for minimal ptosis: the Fasanella-Servat operation. Trans Ophthalmol Soc UK 1973; 93: 425-37.

16 Fox SA. A modified Fasanella-Servat procedure for ptosis. Arch Ophthalmol 1975; 93: 639-40.

Accepted for publication 12 May 1988 